\title{
AVALIAÇÕES DE DESEMPENHO NO ENSINO CONTÁBIL BRASILEIRO: UMA ANÁLISE COMPARATIVA ENTRE IES DIANTE DO EXAME DE SUFICIÊNCIA DO CFC
}

\author{
Performance evaluations in Brazilian accounting education: A compara- \\ tive analysis between IES in front of the CFC Sufficiency Exam
}

Ronan Reis Marçal

E-mail:m.ronanreis@gmail.com

Mestre em Ciências Contábeis pela Universidade Federal do Rio de Janeiro; Doutorando em

Ciências Contábeis na Universidade Federal de Santa Catarina;

Endereço para contato: Rua Engenheiro Agronômico Andrei Cristian Ferreira, s/n, Trindade, 88040900, Florianópolis, Santa Catarina, Brasil.

https://orcid.org/0000-0002-7922-2364

Vinícius da Silva Matos

E-mail: vini_matos83@hotmail.com

Mestre em Ciências Contábeis pela Universidade Federal do Rio de Janeiro; Graduado em Ciências Navais pela Escola Naval; Chefe no Departamento de Gestão Financeira da Marinha do Brasil. https://orcid.org/0000-0003-4563-0279

Thauan Felipe Medeiros de Carvalho E-mail: thauanfelipe@icloud.com

Graduado em Ciências Contábeis pela Universidade Estadual de Feira de Santana; Mestrando em Ciências Contábeis na Universidade Federal do Rio de Janeiro. https://orcid.org/0000-0003-1514-0535

Marcia da Silva Carvalho

E-mail: marcia@facc.ufrj.br

Doutora em Planejamento Energético pela Universidade Federal do Rio de Janeiro; Mestre em Ciências Contábeis pela Universidade Estadual do Rio de Janeiro; Professora adjunta na Universidade Federal do Rio de Janeiro. https://orcid.org/0000-0003-4109-6443

Artigo recebido em 20 de outubro de 2018. Aceito em 5 de agosto de 2019. 


\section{Resumo}

O Exame de Suficiência do Conselho Federal de Contabilidade (CFC) é mencionado por diversos autores como uma ferramenta de avaliação do desempenho de estudantes de Ciências Contábeis. Desde 2011 o exame foi alavancado como condição necessária para a obtenção do registro profissional contábil por meio da Lei 12.249 (2010). Embora o exame tenha sido aplicado ininterruptamente desde a referida Lei, seus resultados não haviam sido divulgados, até então, de forma segregada por Instituição de Ensino Superior (IES). Contudo, em 2017, o CFC disponibilizou os resultados do exame aplicado no primeiro semestre de forma analítica, considerando os resultados auferidos por cada IES. Mediante a relevância do exame e a novidade informacional, este estudo buscou verificar se há diferença no nível de desempenho obtido pelos estudantes de Ciências Contábeis das IES brasileiras no Exame de Suficiência do CFC, considerando as diferentes características dessas IES como possíveis determinantes de desempenho. Foram utilizados métodos quantitativos para a verificação das hipóteses formuladas considerado um nível de confiança de $95 \%$ o tempo todo. Os resultados sugerem diferenças estatisticamente significativas das médias de aprovação no Exame de Suficiência para todas as condições observadas. Os achados deste estudo contribuem para a esfera de pesquisas sobre o ensino contábil no Brasil permitindo análises setoriais nessa vertente.

Palavras-chave: Exame de Suficiência. Ensino contábil. Ensino superior. IES.

\section{Abstract}

The CFC Examination of Sufficiency is mentioned by several authors as a tool for evaluating students' performance in Accounting. Since 2011, the exam was leveraged as a necessary condition to obtain professional accounting registration through Law 12.249 (2010). Although the examination has been applied continuously since the referred Law, its results had not been disclosed, until then, separately by each University. However, in 2017, CFC released the results of the exam applied in the first semester analytically, considering the results obtained by each University. Due to the relevance of the exam and the informational novelty, this study sought to verify if there is a difference in the level of performance obtained by the Accounting students of Brazilian Universities in the CFC Examination of Sufficiency, considering the different characteristics of these Universities as possible determinants of performance. Quantitative methods were used to verify the hypotheses formulated considering a $95 \%$ confidence level all the time. The results suggest statistically significant differences of the means of approval in the Examination of Sufficiency for all the observed conditions. The findings of this study contribute to the sphere of research on accounting education in Brazil allowing sectoral analyzes in this area.

Keywords: Examination of Sufficiency. Accounting education. Higher education. IES.

\section{INTRODUÇÃO}

As constantes mudanças na sociedade, os avanços tecnológicos e as tendências criadas pela globalização requerem dos profissionais das ciências sociais um processo contínuo de atualização de seus conhecimentos. A ciência contábil está inserida nesse contexto e, conforme Bugarim, Rodrigues, Pinho e Machado (2014a), tal ciência tem obtido sucesso nesse processo evolucionário desde sempre. 
Dadas essas circunstâncias, o mercado exige da contabilidade algum parâmetro de qualidade a fim de atestar se determinado indivíduo possui ou não as competências necessárias para o exercício da profissão. Nessa esteira, o artigo 12 do Decreto-Lei 9.295 (1946) teve sua redação alterada pela Lei 12.249 (2010), passando a exigir a aprovação no Exame de Suficiência como condição prévia ao exercício da profissão de contador.

Destarte, o Conselho Federal de Contabilidade (CFC) editou a Resolução CFC 1.486 (2015), que regulamenta o Exame de Suficiência como requisito para obtenção do registro profissional na categoria dos Contadores. Destaca-se, portanto, que o Exame de Suficiência realizado pelo CFC é uma ferramenta de avaliação dos profissionais de contabilidade.

Para Boggino (2009), avaliação não significa classificação, mas compreensão, representando uma peça fundamental no processo de aprendizagem e na qualidade da educação. Nesse contexto, Pinheiro, Dias, Lima e Lopes (2013) mencionam que o processo de aprendizagem e avaliação deve estar voltado não apenas ao cumprimento das expectativas do mercado, mas também para a melhoria da qualidade de vida dos envolvidos no processo.

Em 2017, pela primeira vez em sua história, o CFC divulgou os resultados obtidos pelos participantes do Exame de Suficiência de forma segregada por Instituições de Ensino Superior (IES). Os dados, que são referentes ao exame aplicado no primeiro semestre de 2017, possuem informações analíticas sobre as instituições de ensino, como o tipo da organização, a categoria administrativa e a região demográfica à qual estejam inseridas.

O Exame de Suficiência e as métricas de avaliação do ensino contábil brasileiro têm sido objeto de inúmeros estudos recentes (Bugarim et al., 2014b; Galvão, 2016; Gonzales \& Ricardino Filho, 2017; Miranda, Araújo, \& Miranda, 2017). Dada a relevância do tema, o objetivo deste trabalho foi verificar se há diferença no nível de desempenho auferido pelos estudantes de Ciências Contábeis das IES brasileiras no Exame de Suficiência do CFC, considerando as diferentes características dessas IES como possíveis determinantes de desempenho.

Para atingir o objetivo proposto, este estudo utilizou uma abordagem quantitativa para a análise dos resultados do Exame de Suficiência aplicado no primeiro semestre de 2017, dispostos pelo CFC. Foram realizados testes de diferença de médias entre as instituições de ensino de caráter privado e público; entre as instituições de acordo com sua região demográfica; e, por fim, entre as instituições de acordo com suas organizações acadêmicas, a saber: universidades, faculdades ou centros universitários.

Justifica-se a presente análise pelo seu caráter inédito, tendo em vista que os resultados dos exames de suficiência anteriores ao de 2017 não permitiam as comparações aqui propostas. Espera-se que os achados deste trabalho possam contribuir para o cerne de pesquisas voltadas ao ensino contábil brasileiro ao demonstrar, pela primeira vez, as 
similaridades ou diferenças nos resultados do Exame de Suficiência do CFC em razão de características específicas das instituições de ensino observadas.

Imediatamente após essa breve introdução será apresentada a revisão de literatura acerca do tema. Em seguida, serão expostos o percurso metodológico e as respectivas análises dos resultados obtidos. Por fim, será apresentada a conclusão dos autores acompanhada de sugestões a trabalhos posteriores e das limitações percebidas.

\section{REFERENCIAL TEÓRICO}

Esta seção traz a base teórica para as discussões propostas pelo artigo. Considerando - objetivo do trabalho, nota-se a presença de três aspectos fundamentais a serem compreendidos: as características e o histórico das instituições de ensino superior brasileiras; - Exame de Suficiência disposto pelo CFC; e a qualidade do ensino contábil no Brasil. Também são apresentados, ao final desta seção, alguns estudos correlatos abordando especificamente o Exame de Suficiência do CFC ou, ainda, outras medidas de mensuração de aprendizado.

\subsection{HISTÓRICO DAS INSTITUIÇÕES DE ENSINO SUPERIOR E DO ENSINO CONTÁBIL NO BRASIL}

A chegada da Coroa Real Portuguesa ao Brasil no século XIX marca o início da disseminação do Ensino Superior no País. Contudo, sua concretização ocorre somente em 1827, com a Faculdade de Direito de Olinda e a Academia de Direito de São Paulo-Faculdade de Direito de São Paulo, com o objetivo de formar os futuros governantes e administradores públicos para o País (Barreto \& Filgueiras, 2007).

Décadas mais tarde, em 1920, destaca-se o surgimento da Universidade do Brasil, atualmente denominada Universidade Federal do Rio de Janeiro, resultado da integração da Escola Politécnica, da Faculdade de Medicina e da Faculdade de Direito (Silva, 2008). Ainda de acordo com essa autora, um outro marco histórico no Ensino Superior no Brasil decorre da criação do Ministério da Educação (MEC), em 1930, precedendo uma reforma educacional, que resultou na criação do primeiro Estatuto da Universidade Brasileira.

No final da década de 1990, a Lei das Diretrizes e Bases da Educação Nacional (LDB) (Lei 9.394, 1996) viabilizou a autonomia universitária, promovendo a aplicação do acesso ao Ensino Superior. Consequentemente, após esse período, houve um crescimento expressivo de novas instituições. 


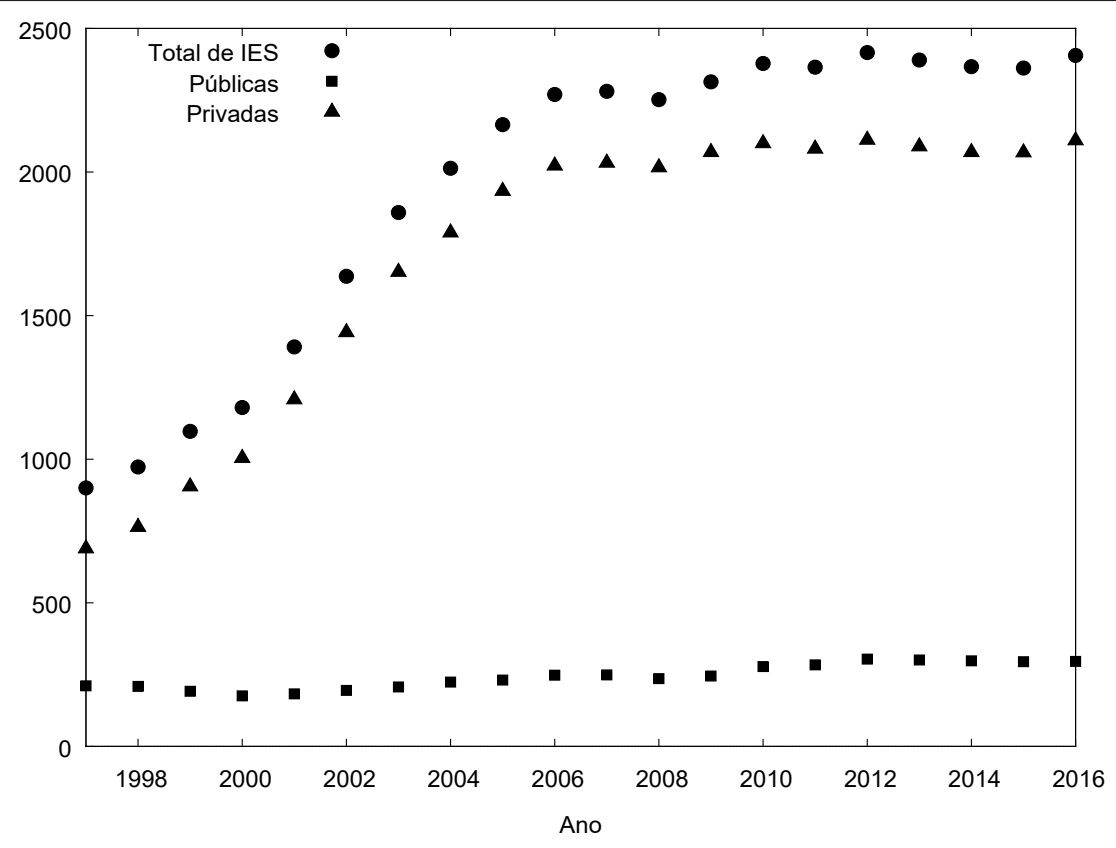

Figura 1. Evolução de IES públicas e privadas (1997-2016). Adaptada de "Sinopses Estatísticas da Educação Superior," por Instituto Nacional de Estudos e Pesquisas Educacionais Anísio Teixeira [INEP], 2018. Recuperado de http://portal.inep.gov.br/web/guest/sinopses-estatisticas-da-educacao-superior

Embora a Figura 1 demonstre que há uma notória evolução do número de IES no período pós-LDB, ressalta-se que tal aumento decorre em razão das instituições privadas. No período analisado, enquanto as IES privadas cresceram acentuadamente, passando de 689 para 2.110 instituições, o número de IES públicas evoluiu de 211 para 296, permanecendo próximo da linearidade.

Para Martins, Vasconcelos e Aguiar (2009), o acesso ao ensino superior passou a ser possível a todas as classes somente com o crescimento do ensino do setor privado, uma vez que, anteriormente, com a prevalência do setor público, tal acesso era restrito às classes sociais mais privilegiadas.

O MEC, por sua vez, sistematiza as IES em três tipos: faculdades, centros universitários e universidades. Tal classificação está prevista no Decreto 9.235 (2017):

Tabela 1

Tipos Instituições de Ensino Superior

\begin{tabular}{|c|c|c|}
\hline Faculdades & Centros universitários & Universidades \\
\hline $\begin{array}{l}\text { Não possuem prerroga- } \\
\text { tivas de autonomia. São } \\
\text { focadas em apenas uma } \\
\text { área do conhecimento e } \\
\text { são a origem de qualquer } \\
\text { tipo de IES. }\end{array}$ & $\begin{array}{l}\text { Instituições de Ensino Superior com ma- } \\
\text { trizes pluricurriculares abrangendo uma } \\
\text { ou mais áreas do conhecimento. Essas } \\
\text { IES possuem prerrogativa para a criação, } \\
\text { organização e extinção de cursos de nível } \\
\text { superior. Obrigatoriamente um terço do seu } \\
\text { corpo docente com titulação de mestrado } \\
\text { ou doutorado. }\end{array}$ & $\begin{array}{l}\text { São indissociáveis das atividades de } \\
\text { ensino, pesquisa e extensão. Também } \\
\text { detêm a prerrogativa de autonomia } \\
\text { e seu corpo docente é constituído } \\
\text { obrigatoriamente por, no mínimo, um } \\
\text { terço de mestres elou doutores. }\end{array}$ \\
\hline
\end{tabular}

Nota. Adaptada da "Lei 9.235," 2017. 
Atualmente, a principal forma de ingresso no ensino superior do Brasil ocorre diante do Exame Nacional do Ensino Médio (ENEM). Tal Exame foi criado em 1998 como uma modalidade alternativa ou complementar perante os exames de acesso de cursos profissionalizantes pós-médios e do Ensino Superior (INEP, 2002).

Posteriormente o ENEM assumiu outras finalidades, como a condição de pré-requisito para concessão bolsas de estudo e financiamento de cursos em instituições privadas. Destacase, ainda, a sua obrigatoriedade para acesso ao ensino superior público a partir da criação do Sistema de Seleção Unificada (SISU), em 2012. O ENEM vem ganhando notoriedade no âmbito acadêmico nos últimos anos. Viggiano e Mattos (2013), por exemplo, inferiram haver três grupos com relação ao desempenho desse exame seccionados regionalmente: superior (Sul e Sudeste), médio (Centro-Oeste) e inferior (Norte e Nordeste).

Passando a abordar especificamente o ensino da contabilidade no Brasil, pode-se dizer que o seu início foi tardio. De acordo com Peleias, Silva, Segreti, e Chirotto (2007), o marco inicial ocorreu no século XIX, mas sem o rótulo de Ciências Contábeis, com a formalização das aulas de Comércio e do Instituto Comercial do Rio de Janeiro. Ainda, as aulas de Comércio seriam alçadas ao posto de nível superior em 1891 com a Sociedade Anônima Academia de Comércio (Candiotto \& Miguel, 2009).

O Curso de Ciências Contábeis em si emergiu apenas em 1945, com o advento do Decreto-Lei n. 7.988 (1945), que concedeu o título de Bacharel em Ciências Contábeis aos concluintes desse Curso. No ano seguinte, em 1946, surgiram o Conselho Federal de Contabilidade (CFC) e os Conselhos Regionais de Contabilidade (CRCs) com o Decreto-Lei 9.295 (1946). Isso foi, conforme Espejo, Ribeiro, Silva e Oliveira (2017), um importante passo para o reconhecimento da contabilidade no Brasil.

Conforme dados do INEP (2018), a partir de 1999 houve uma acentuada evolução no número de cursos de contabilidade ofertados por IES no Brasil. Cabe mencionar que, no período de 2011 a 2016, o número de IES que ofertam o Curso de Bacharelado em Ciências Contábeis subiu de 856 para 995 instituições. Enquanto as IES públicas permaneceram oferecendo o curso em 95 unidades, a rede privada apresentou uma ampliação de 761 para 900 unidades que disponibilizam o Curso.

\subsection{EXAME DE SUFICIÊNCIA DO CFC}

O Conselho Federal de Contabilidade, por meio da Resolução CFC 853 (1999) instituiu o Exame de Suficiência como um dos requisitos para a obtenção de registro profissional em contabilidade. Segundo a norma, vários aspectos motivaram a instituição do Exame de Suficiência. Inicialmente, destaca-se que o Decreto-Lei 9.295 (1946) exige o prévio deferimento do Registro Profissional do CRC para o exercício da profissão de Contabilista. Assim, o uso 
do exame de suficiência como requisito para obtenção do registro profissional ocupa a função de fiscalização preventiva do exercício da profissão (Resolução 853, 1999).

Miranda et al. (2017) mencionam que, conforme o artigo $2^{\circ}$ da Resolução CFC 853 (1999), o Exame de Suficiência busca atestar o alcance de conhecimentos médios, de acordo com os conteúdos programáticos trabalhados no Curso de Bacharelado em Ciências Contábeis. Gonzales e Ricardino (2017) destacam que embora os objetivos do exame de suficiência pudessem ser considerados benéficos, houve contestações quanto à competência do CFC para instituí-lo e regulamentá-lo. Desse modo, a questão passou a ser tratada na esfera judicial, que decidiu pela suspensão do Exame em 2005.

Para Lopes (2009), essa decisão judicial fundamentou-se no fato de que o Exame de Suficiência havia sido instituído por meio de resolução do CFC e não por lei, o que contraria o Princípio Constitucional do Livre Exercício Profissional. O referido Princípio é garantido pelo inciso XIII do artigo $5^{\circ}$ da Constituição Federal (1988), em que é estabelecido que "é livre o exercício de qualquer trabalho, ofício ou profissão, atendidas as qualificações profissionais que a lei estabelecer".

Segundo Miranda et al. (2017), a partir da interrupção da aplicação do Exame de Suficiência ocorrida em 2005, o CFC buscou restabelecer o Exame por meio de lei. Assim, em junho de 2010 foi sancionada a Lei 12.249, que alterou dispositivos do Decreto-Lei 9.295 (1946) e permitiu ao CFC regular o Exame de Suficiência. Desde 2011 a prova tem sido aplicada como requisito à obtenção do registro profissional, mantendo-se o nível mínimo de acerto de $50 \%$ das questões, seguindo o mesmo padrão do exame aplicado anteriormente.

Cabe a cada Conselho Regional de Contabilidade a divulgação do exame em suas devidas jurisdições-com aplicação uniforme em todo o Brasil-abordando diversas áreas do conhecimento, como: Língua Portuguesa, Matemática Financeira, Noções de Direito, Ética Profissional, Teoria da Contabilidade, Contabilidade Geral, Contabilidade de Custos, Contabilidade Pública, Auditoria Contábil e outras (Nogueira, Nogueira, Almeida, Ribeiro, \& Chaves, 2013).

Diehl e Souza (2007) e Galvão (2016) sugerem a aceitação do exame pelos profissionais contabilistas, enquanto Santos, Pinto, Gonçalves e Nunes (2013) indicam a sua aprovação pelos docentes. Já Miranda et al. (2017) denotam a aceitação do exame por ambas as referidas classes.

Quanto à percepção por parte dos discentes, Lima, Silva, Campelo e Gonçalves (2012) evidenciam que estes concordam com o exame de suficiência. Ainda, tem-se que os alunos consideram o exame importante para a sua empregabilidade e formação, representando a etapa final para a consolidação do investimento feito ao longo da graduação (Nogueira et al., 2013).

Nessa linha de pensamento, Kounrouzan (2011) afirma que: 
A formação adequada do profissional vai desde a escolha da entidade formadora até a educação complementar e continuada necessária, de modo a adequar-se ao atual cenário de qualificação e formação que o mercado necessita. O Exame de suficiência será o balizador dessa formação, através das provas aplicadas, também postergando elou impedindo a entrada no mercado de trabalho do Contador que não tenha a formação mínima para o desempenho da profissão (p. 24).

De acordo com Bugarim et al. (2014a), o exame de suficiência representa um esforço do CFC no sentido de buscar minimizar algumas falhas do ensino contábil, procurando atender à necessidade de melhoria na qualidade dos serviços prestados pelos contabilistas. Nesse sentido, Kounrouzan (2011) destaca que o exame proporcionou uma maior conscientização dos profissionais contabilistas no cumprimento de suas obrigações, bem como uma maior valorização dos contadores pelo mercado de trabalho.

Passando a tratar da importância do exame de suficiência para as instituições de ensino superior, Madeira, Mendonça, e Abreu (2003) defendem que o exame deveria funcionar como ferramenta de suporte às IES, colaborando com o processo de avaliação e acompanhamento dos cursos, uma vez que os conteúdos exigidos nas provas podem ser comparados àqueles trabalhados nos cursos.

Kounrouzan (2011) sustenta ainda que o objetivo do exame não se limita a avaliar os conhecimentos técnicos dos candidatos, mas busca especialmente estimular a atualização das instituições de ensino superior, a fim de que estas acompanhem com a mesma intensidade a velocidade com que as mudanças ocorrem.

\subsection{ESTUDOS ANTERIORES SOBRE DESEMPENHO NO ENSINO CONTÁBIL}

Quanto às características dos exames utilizados para mensurar o desempenho do ensino contábil, Pinheiro et al. (2013) investigaram se as provas do Exame Nacional do Desempenho dos Estudantes (Enade) e do Exame de Suficiência são aderentes ao perfil do Contador estabelecido pelo Conselho Nacional de Educação (CNE). A pesquisa sugere que o Enade demonstrou um nível maior de abrangência ao mensurar a performance dos estudantes considerando habilidades de maior domínio cognitivo.

Por sua vez, no que diz respeito ao nível das questões, Miranda et al. (2017) afirmam que, de modo geral, as questões utilizadas nas provas do Exame de Suficiência foram consideradas medianas por docentes e profissionais da área contábil.

Passando a abordar a relevância de tais exames para as IES, nota-se que os resultados das provas podem servir para a atualização das grades curriculares das IES. Um exemplo 
disso é o estudo de Martins, Silva, Bernardo e Madeira (2003), no qual se constatou a necessidade de aperfeiçoamento no ensino da disciplina Teoria da Contabilidade nas IES do Estado de Minas Gerais, após comparação entre a performance dos candidatos desse Estado e a dos candidatos das demais regiões do País.

Face à sua importância para as IES, Gonzales e Ricardino (2017) defendem a transparência na divulgação dos resultados do Exame de Suficiência do CFC, destacando a utilidade informacional trazida pela divulgação de índices de aprovação por instituição. Para os autores, essas informações possuem utilidade para as empresas contratantes de profissionais contábeis, para o próprio CFC e para os estudantes, docentes e coordenadores de cursos na área contábil. Além disso, Miranda et al. (2017) mencionam que, na percepção dos docentes, os resultados positivos no exame de suficiência são relevantes para a imagem das IES.

Especificamente acerca do desempenho de IES no exame de suficiência, Kounrouzan (2011) buscou comparar os resultados da primeira fase do exame (2000 a 2004) com a primeira edição do exame no ano de 2011. A pesquisa indicou que houve uma queda significativa no nível de aprovação, sugerindo um enfraquecimento na qualidade do ensino.

Kounrouzan (2011) destacou ainda que melhorias precisam ser realizadas para adequar o profissional ao mercado. Para o autor, o baixo nível de aprovação no Exame de Suficiência deve incentivar as IES a aprimorarem os conteúdos ministrados nas disciplinas que contemplam a grade curricular dos cursos de graduação. Do contrário, estas podem perder alunos para IES que apresentem desempenhos satisfatórios no Exame.

Bugarim et al. (2014a) indicam que, no período de 2000 a 2012, houve uma significativa diminuição do índice de aprovação no exame de suficiência. Segundo os autores, embora a taxa nacional média no período seja de $59,7 \%$, houve uma queda de $83,52 \%$ de aprovação na edição do primeiro semestre de 2000 para apenas $23,78 \%$ em 2012. Assim, a ideia de que a obrigatoriedade do exame de suficiência levasse as IES ao aperfeiçoamento de seus cursos não se concretizou.

Abordando o desempenho no exame de suficiência sob um prisma regional, Bugarim et al. (2014a) mostraram que a região Sul apresentou a maior taxa média de aprovação $(57,8 \%)$. O Estado do Sergipe, com $69,3 \%$, obteve a maior média de aprovação, e o Estado do Mato Grosso teve a menor média (38,7\%).

Em outro estudo, Bugarim et al. (2014b) analisaram os resultados do Exame de Suficiência aplicados em dois períodos, sendo o primeiro de 2000 a 2004, e o segundo compreendido pelos anos de 2011 e 2012. O estudo observou o desempenho dos candidatos por disciplina e por unidade da Federação, concluindo que, em geral, ocorreu uma piora de desempenho ao longo das edições do exame. 
Tabela 2

Desempenho relativo das Unidades Federativas (UF) no Exame de Suficiência

\begin{tabular}{ll}
\hline \multicolumn{1}{c}{ Comportamento nos grupos } & \multicolumn{1}{c}{ UF } \\
\hline Grupo com melhor desempenho nos dois períodos. & BA, CE, DF, SE, RR, PE, RJ, e RN \\
Grupo com pior desempenho nos dois períodos. & AP, AM, GO, MS, PA, RO e TO \\
Migrou do grupo de melhor desempenho para o de pior desempenho. & AC, MA, MG e RS \\
Migrou do grupo de pior desempenho para o de melhor desempenho. & AL, ES, MT, PB, PR, PI, SC e SP \\
\hline
\end{tabular}

Nota. Adaptada de "Desempenho dos Profissionais de Contabilidade no Exame de Suficiência do CFC: Uma análise de conglomerados regionais," por M. C. C. Bugarin, L. L. Rodrigues, J. C. C. Pinho, e D. Q. Machado, 2014a, Revista de Contabilidade e Organizações, 8, pp. 60-71.

Da Tabela 2, os autores ressaltam que do grupo composto pelas UF que mantiveram melhor desempenho nos dois períodos, cinco fazem parte da Região Nordeste (BA, CE, SE, $P E$ e RN). Do contrário, o estudo destaca que o grupo das UF com desempenho inferior em ambos os períodos é formado por cinco Estados da Região Norte (AP, AM, PA, RO e TO) (Bugarim et al., 2014a).

Outras pesquisas se dedicaram ao estudo do desempenho do ensino contábil por meio do Enade, como Silva, Gomes e Guimarães (2008), em que se defendeu que mesmo com as consideráveis mudanças ocorridas no ensino contábil nacional, os estudantes de contabilidade apresentaram baixo desempenho no Enade de 2006.

Santos et al. (2014) buscaram correlacionar a composição do corpo docente de 34 IES do Estado do Rio de Janeiro com os respectivos percentuais de aprovação no Exame de Suficiência e com os conceitos do Enade. De acordo com a pesquisa, o aumento na quantidade de mestres e doutores nas IES não se refletiu em melhora da taxa de aprovação de seus alunos no Exame de Suficiência. Além disso, a pesquisa indicou a ausência de impacto positivo com relação ao Enade.

Camargo, Camargo, Andrade e Bornia (2016) avaliaram a proficiência dos graduandos de Ciências Contábeis no Enade de 2012, tendo sugerido que a prova representou um grau de dificuldade elevado para os estudantes. Ainda, segundo Camargo et al. (2016), a baixa proficiência dos estudantes fica comprovada independentemente de aspectos regionais ou do fato de cursar a graduação em IES privada ou pública. Os autores destacam que esse desempenho ruim já havia sido observado anteriormente no campo da contabilidade.

Por fim, alguns trabalhos tentaram apresentar os determinantes do baixo desempenho do ensino contábil, como o de Nascimento e Souza (2005), os quais realizaram uma pesquisa com os coordenadores de 16 Cursos de Ciências Contábeis do Estado do Paraná. Segundo o estudo, a maioria dos coordenadores concorda que o grau de preparo dos egressos, para o exercício profissional da contabilidade, pode ser indicado pelos resultados do exame de suficiência. 
Baseado nos resultados dos exames de suficiência analisados, Nascimento e Souza (2005) indicaram que a maioria dos cursos possuía qualidade insuficiente. De acordo com os autores, o regime de trabalho inadequado do corpo docente e a falta de preparo dos estudantes para o ensino superior são apontados como causas dessa falta de eficiência. Segundo Nogueira et al. (2013), muitos alunos não se sentem prontos para a realização do exame de suficiência, embora os estudantes tenham se mostrado satisfeitos quanto à qualidade do ensino recebido.

\section{METODOLOGIA}

De acordo com Gil (2010), este estudo é classificado como descritivo, uma vez que busca retratar as características de uma determinada população. Ademais, com relação à abordagem utilizada, o presente trabalho dispõe de métodos quantitativos, como a coleta de dados seguida de tratamento e análise destes (Martins \& Theóphilo, 2009).

Visando cumprir o objetivo proposto, foram utilizadas ferramentas de estatística descritiva e efetuados testes de diferença de médias. Tais testes exigem dados métricos, sejam eles contínuos ou discretos, e destinam-se a avaliar afirmações feitas sobre as médias das populações estabelecidas diferenciando os resultados entre discrepâncias amostrais ou não (Stevenson, 1981).

A amostra da pesquisa é do tipo não probabilística, visto que foram coletadas informações pertinentes ao índice de aprovação e de ausência dos alunos de Instituições de Ensino Superior (IES) do relatório de resultados do Exame de Suficiência do primeiro semestre de 2017 apresentado pelo CFC. Na fase de tratamento dos dados foram eliminadas as observações referentes às instituições que obtiveram índice de ausência de 100\% no referido exame. Ao final, a amostra gerada remeteu a um total de 1.499 observações, composta da seguinte forma:

Tabela 3

Classificação das IES de acordo com a categoria administrativa e com a organização acadêmica

\begin{tabular}{ccccccc}
\hline \multicolumn{3}{c}{ Categoria administrativa } & \multicolumn{5}{c}{ Organização acadêmica } \\
\hline Privada & Pública & Total & Centro Universitário & Faculdade & Universidade & Total \\
\hline 1.371 & 128 & 1.499 & 207 & 909 & 383 & 1.499 \\
\hline
\end{tabular}

Tabela 4

Classificação das IES de acordo com a região

\begin{tabular}{cccccc}
\hline \multicolumn{7}{c}{ Região demográfica } \\
\hline Centro-Oeste & Nordeste & Norte & Sudeste & Sul & Total \\
\hline 177 & 326 & 131 & 569 & 296 & 1.499 \\
\hline
\end{tabular}


A segregação das IES de acordo com suas categorias administrativas está prevista na Lei 9.394 (1996), ao passo que a classificação em razão de suas organizações acadêmicas é descrita no artigo 15 do Decreto 9.235 (2017). Além disso, foi feita uma divisão das IES conforme a região demográfica em que estão inseridas, conforme a Tabela 4.

Com base na revisão de literatura, em decorrência da relevância e da utilidade do Exame de Suficiência do CFC para as IES, adotou-se o desempenho no exame como proxy para analisar o nível de desempenho dos graduandos do ensino contábil no Brasil. Dadas as três classificações das IES, demostradas nas Tabelas 1 e 2, as seguintes hipóteses foram desenvolvidas e verificadas neste estudo:

H1: Existe diferença de desempenho do ensino contábil brasileiro de acordo com a categoria administrativa das IES.

H2: Existe diferença de desempenho do ensino contábil brasileiro de acordo com a organização acadêmica das IES.

H3: Existe diferença de desempenho do ensino contábil brasileiro de acordo com a região demográfica das IES.

As hipóteses $\mathrm{H1}, \mathrm{H} 2$ e $\mathrm{H} 3$ foram testadas de acordo com os resultados obtidos nos testes de diferença de médias dos índices de aprovação das IES. Visando uma análise mais abrangente, o estudo considera também a estatística descritiva dos dados, o que permitiu identificar em quais subcategorias as médias de aprovação no Exame de Suficiência foram maiores ou menores.

As estatísticas descritivas, bem como os testes de diferença de médias, foram efetuadas por meio do software IBM SPSS ${ }^{\circ}$ em sua versão de número 22 . Ressalta-se que, para as análises, foi considerado sempre um nível de confiança de 95\%.

\section{ANÁLISE DE RESULTADOS}

A primeira fase da análise dos resultados foi a verificação dos pressupostos de normalidade e homocedasticidade dos dados. De acordo com os ensinamentos de Fávero, Belfiore, Silva e Chan (2009), a normalidade foi testada por meio do teste de KolmogorovSmirnov (KS), já que as subamostras deste estudo são sempre superiores a 30 observações. Com relação à homocedasticidade, ainda conforme os autores, o teste mais adequado é o teste de Levene. 
Para os testes dos pressupostos, de acordo com a categoria administrativa das IES, os resultados indicaram a rejeição da homocedasticidade das variâncias e a aceitação parcial da normalidade (apenas para as IES públicas). Assim, para verificar a $\mathrm{HI}$, foi feito um teste não paramétrico, ferramenta adequada para tal situação, de acordo com Gujarati e Porter (2011). Por se tratar de um caso com apenas duas amostras (pública e privada) e por serem estas, independentes entre si, foi utilizado o teste de Mann-Whitney, seguindo os ensinamentos de Fávero et al. (2009).

Tabela 5

Médias do índice de aprovação-Categoria administrativa

\begin{tabular}{cc}
\hline U de Mann-Whitney & 43195,500 \\
\hline$Z$ & $-9,553$ \\
\hline Significância Sig. (2 extremidades) & 0,000 \\
\hline
\end{tabular}

Na Tabela 5 é possível observar que o teste aponta um p-valor de 0,000. Com isso, dado o nível de significância proposto (5\%), a hipótese nula é rejeitada, portanto, de acordo com os resultados, é possível inferir que existe diferença estatisticamente significativa entre as médias de aprovação no Exame de Suficiência quando se trata de IES públicas versus IES privadas. Dessa forma, a $\mathrm{Hl}$ foi aceita, ou seja: há sim diferença no desempenho do ensino contábil brasileiro de acordo com a categoria administrativa das IES.

Além disso, cabe destacar que, por meio da análise das estatísticas descritivas das duas categorias administrativas em estudo, as IES públicas auferiram melhores resultados no Exame de Suficiência observado, tendo apresentado uma média de aprovação de 44,09\% contra uma taxa média de aprovação de $21,68 \%$ das IES privadas.

Este resultado está em desacordo com o resultado encontrado por Camargo et al. (2016), em que os autores não sugerem evidências de diferença entre o desempenho de estudantes de instituições públicas ou privadas no Enade. Com isso, aparentemente, existem diferenças entre - Exame de Suficiência do CFC e o Enade no que se refere à avaliação de desempenho de estudantes de Ciências Contábeis, fato já apontado por Pinheiro et al. (2013).

Em sequência, para verificar a $\mathrm{H} 2$, testaram-se os pressupostos de normalidade e homocedasticidade para os dados conforme a organização acadêmica das IES. Os pressupostos não foram atendidos, o que implicou a adoção de um teste não paramétrico para a análise dessa hipótese. Considerando isso e o fato de tratar-se de mais de duas amostras independentes, o teste adequado para inferir sobre as médias é, segundo Fávero et al. (2009), o teste de Kruskal Wallis. 
Tabela 6

Médias do índice de aprovação-Organização acadêmica

\begin{tabular}{cl}
\hline Qui-quadrado & 39,479 \\
\hline Significância Sig. (2 extremidades) & 0,000 \\
\hline
\end{tabular}

Dado o p-valor de 0,000, inferior ao nível de 5\% de significância, a hipótese nula do caso é rejeitada. Portanto, é possível afirmar que para a amostra selecionada e considerando um índice de confiança de $95 \%$, existe diferença estatisticamente significativa entre as médias dos índices de aprovação das IES em razão do tipo de organização acadêmica. E, assim, a H2 deste estudo também foi aceita, ou seja: há diferença de desempenho do ensino contábil no Brasil quando se trata de IES de diferentes formatos organizacionais acadêmicos.

A fim de verificar se a desigualdade ocorre em todos os sentidos, foram efetuados testes par a par (Mann-Whitney). De acordo com os resultados constantes na Tabela 7, não há diferença de médias de aprovação entre centros universitários e universidades. Somente existem diferenças estatisticamente significativas quando as faculdades estão envolvidas nos pares.

Tabela 7

Resultados par a par-Organização acadêmica

\begin{tabular}{lc} 
& Centro universitário-Faculdade \\
\hline U de Mann-Whitney & 74246,000 \\
Significância Sig. (Bicaudal) & 0,000 \\
\hline & Centro universitário-Universidade \\
\hline U de Mann-Whitney & 39071,500 \\
Significância Sig. (Bicaudal) & 0,772 \\
\hline & Faculdade-Universidade \\
\hline U de Mann-Whitney & 142734,000 \\
Significância Sig. (Bicaudal) & 0,000 \\
\hline
\end{tabular}

Além disso, conforme os resultados dispostos na Tabela 8, é possível inferir que tal discrepância das faculdades é apresentada com um cunho negativo em seus resultados, visto que a média de aprovação das faculdades foi a menor entre as três amostras consideradas.

Tabela 8

Médias de aprovação-Organização acadêmica

\begin{tabular}{ccc}
\hline Organização acadêmica & Média de aprovação & Ranking \\
\hline Centro universitário & $26,31 \%$ & $2^{\circ}$ \\
Faculdade & $20,74 \%$ & $3^{\circ}$ \\
Universidade & $28,89 \%$ & $1^{\circ}$ \\
\hline
\end{tabular}


Embora Santos et al. (2014) tenham indicado que o incremento no número de mestres e doutores nas IES não refletiu em melhora da taxa de aprovação de seus alunos no exame de suficiência, no presente estudo observou-se que as IES que são obrigadas a manter ao menos um terço de seu corpo docente com titulação acadêmica de mestrado ou doutorado, como é o caso das universidades e centros universitários, obtiveram um desempenho superior aos das faculdades, que não precisam cumprir tal exigência.

Por fim, foram testados os pressupostos para as amostras segundo as regiões demográficas das IES. Mais uma vez os testes de pressupostos apresentaram violação unânime de normalidade e da homocedasticidade, sendo aplicado então um teste não paramétrico para a verificação da $\mathrm{H} 3$. Por ser também uma condição de mais de duas amostras independentes, foi novamente utilizado o teste de Kruskal Wallis.

Tabela 9

Médias do índice de aprovação-Região demográfica

\begin{tabular}{cc}
\hline Qui-quadrado & 133,560 \\
\hline Significância Sig. (2 extremidades) & 0,000 \\
\hline
\end{tabular}

Dado um p-valor inferior ao nível de significância de 0,05, a hipótese nula foi rejeitada, demonstrando, portanto, a existência de diferença estatisticamente significativa nas médias dos índices de aprovação do Exame de Suficiência quando levada em conta a região demográfica de cada IES. Destarte, a H3 foi aceita, resultando na inferência de que o desempenho do ensino contábil brasileiro é diferente frente às distintas regiões demográficas das IES.

A Tabela 10 apresenta os resultados par a par das regiões demográficas diante do teste de Mann-Whitney, no qual se percebe que, com p-valores maiores que $5 \%$, os pares Centro-Oeste/Nordeste; Centro-Oeste/Norte e Sudeste/Sul não possuem diferença estatisticamente significativa para suas respectivas médias de aprovação. Para todos os demais casos, há diferença estatisticamente significativa de tais médias.

Tabela 10

Resultados par a par-Região demográfica

\begin{tabular}{ccc}
\hline Par observado & U de Mann-Whitney & Significância Sig. (Bicaudal) \\
\hline Centro-Oeste/Nordeste & 27318,000 & 0,320 \\
Centro-Oeste/Norte & 10911,000 & 0,373 \\
Centro-Oeste/Sudeste & 33646,500 & 0,000 \\
Centro-Oeste/Sul & 16588,500 & 0,000 \\
Nordeste/Norte & 18787,000 & 0,043 \\
Nordeste/Sudeste & 66510,000 & 0,000 \\
Nordeste/Sul & 32724,500 & 0,000 \\
Norte/Sudeste & 21241,000 & 0,000 \\
Norte/Sul & 10631,500 & 0,000 \\
Sudeste/Sul & 78458,000 & 0,098 \\
\hline
\end{tabular}


Nota-se que a região Sul e a região Sudeste são iguais apenas entre si, divergindo de todas as demais. Norte e Nordeste apresentam médias de aprovação igual ao Centro-Oeste, porém divergem de todas as demais e, inclusive, entre si. Já a região Centro-Oeste, como dito, iguala-se ao Norte e ao Nordeste e difere da dupla Sul-Sudeste. A Tabela 11 demonstra as posições no ranking de aprovação:

Tabela 11

Médias de aprovação-Região demográfica

\begin{tabular}{ccc}
\hline Região demográfica & Média de aprovação & Ranking \\
\hline Centro-Oeste & $16,44 \%$ & $4^{\circ}$ \\
Nordeste & $18,11 \%$ & $3^{\circ}$ \\
Norte & $13,16 \%$ & $5^{\circ}$ \\
Sudeste & $27,84 \%$ & $2^{\circ}$ \\
Sul & $30,35 \%$ & $1^{\circ}$ \\
\hline
\end{tabular}

Observando os resultados das Tabelas 10 e 11 concomitantemente, nota-se que o ensino contábil no Brasil está segmentado de forma que a dupla Sul/Sudeste lidera o País em termos de avaliações de desempenho. A região Norte é a que apresenta os piores resultados, a região Nordeste apresenta resultados medianos e, por fim, a região CentroOeste é um meio-termo entre os resultados medianos e os piores resultados.

A indicação de que a região Norte apresenta os piores desempenhos no Exame de Suficiência é corroborada pela pesquisa de Bugarim et al. (2014b), mas, ao mesmo tempo, os autores demonstram que a região Nordeste apresenta os melhores índices de aprovação, diferentemente dos achados do presente artigo. Essas desigualdades podem decorrer em razão dos diferentes períodos observados, resultando em possíveis mudanças em termos médios nos grupos observados.

A liderança da região Sul também foi encontrada por Bugarim et al. (2014a) e os resultados medianos da região Nordeste estão de acordo com a pesquisa de Nogueira et al. (2013) ao apontarem que os alunos dessa região se sentem despreparados para a realização do Exame.

\section{CONCLUSÃO}

Este trabalho teve como objetivo verificar a possível diferença de desempenho do ensino contábil oferecido em instituições de ensino do Brasil de acordo com suas características por meio dos resultados do Exame de Suficiência do CFC. Tal Exame foi apontado por autores como Lopes (2009), Kounrouzan (2011) e Galvão (2016) como uma válida ferramenta de 
mensuração do desempenho dos alunos de Ciências Contábeis e, além disso, a aprovação nesse teste é condição necessária para o efetivo exercício da profissão contábil mediante dispositivos legais.

Embora o Exame de Suficiência do CFC tenha sido aplicado ininterruptamente desde 2011, com o auxílio da Lei 12.249 (2010), os resultados do teste sempre foram apresentados de forma generalizada. Porém, em 2017, o CFC inovou e apresentou dados segregados por IES. Com base nessa modernidade, este trabalho valeu-se dos resultados do Exame de Suficiência do primeiro semestre de 2017 para atingir o objetivo proposto.

O estudo propôs, então, três possíveis condições de discrepâncias do desempenho do ensino contábil: categorias administrativas das IES; organizações acadêmicas das IES; e regiões demográficas das IES. Tais condições resultaram, respectivamente, nas hipóteses $\mathrm{H} 1, \mathrm{H} 2$ e H3, que, durante a fase de análise, foram validadas, permitindo inferir que há diferença estatisticamente significativa no desempenho do ensino contábil em decorrência das características das IES observadas.

Com relação às categorias administrativas, as IES públicas obtêm vantagem na média de aprovação no Exame de Suficiência quando comparadas às IES de cunho privado. Quanto às organizações acadêmicas, as universidades lideram o ranking de aprovação, porém não há diferença significativa estatisticamente com os centros universitários, que estão na segunda posição. $O$ destaque fica a cargo das faculdades que destoam estatisticamente dos outros tipos de IES e ficam na última posição do ranking.

No que diz respeito à análise por regiões demográficas, foi verificada uma liderança de resultados por parte da região Sul, todavia, a região Sudeste, segunda colocada no ranking, não é diferente estatisticamente da região líder, sugerindo, assim, a ideia de que há, na verdade, uma dupla mantendo os melhores resultados do Exame. Essa ideia fica confirmada ao verificar a diferença estatística das médias dessas regiões com todas as outras.

A região Norte apresentou os piores resultados e a região Nordeste apontou resultados médios. As duas regiões possuem médias diferentes entre si e de todas as outras, exceto da região Centro-Oeste. Esta, por sua vez, surge como o meio-termo entre os valores mais baixos (Norte) e os valores medianos (Nordeste).

Alguns resultados estão de acordo com trabalhos similares, como os de Pinheiro et al. (2013), Nogueira et al. (2013) e Bugarim et al. (2014a), enquanto outros estão em sentido oposto a trabalhos anteriores, como os de Santos et al. (2014) e Camargo et al. (2016). Cabe destacar que a similaridade ou diferença desses achados pode ocorrer em razão dos diferentes períodos observados diante dos Exames de Suficiência. Esta é, portanto, a principal limitação deste trabalho, visto que a análise é válida unicamente para o Exame de Suficiência do primeiro semestre de 2017, não podendo ser feito qualquer tipo de generalização. 
Os resultados encontrados podem auxiliar o campo de pesquisas do ensino contábil brasileiro, já que não há trabalho anterior que apresente as diferenças de resultados do ensino contábil das IES pelo Exame de Suficiência, em razão do fato da inédita divulgação de tais dados pelo CFC.

Como sugestão para trabalhos posteriores, indica-se a manutenção da metodologia proposta com um aumento amostral mediante a aplicação de novos Exames de Suficiência que, espera-se, tenham seus resultados divulgados analiticamente pelo CFC de igual forma ao ocorrido em 2017.

Outra sugestão seria analisar os fatores determinantes para as discrepâncias observadas nos resultados desta pesquisa, a exemplo de informações acerca do número de professores doutores em cada IES (ou em termos médios por região); variáveis de caráter socioeconômico, como o PIB regional, entre outras. Nessa sugestão, o uso de análises de regressões lineares se faz aparentemente adequado ao considerar o percentual de aprovação no Exame do CFC como uma variável de resposta.

\section{REFERÊNCIAS}

Barreto, A. L., \& Filgueiras, C. A. L. (2007). Origens da Universidade Brasileira. Química Nova, 30(7), 1780-1790.

Boggino, N. (2009). A avaliação como estratégia de ensino. Revista de ciências da educação, 9(2), 79-86.

Bugarim, M. C. C., Rodrigues, L. L., Pinho, J. C. C., \& Machado, D. Q. (2014a). Análise Histórica dos Resultados do Exame de Suficiência do Conselho Federal de Contabilidade. Revista de contabilidade e controladoria, 6(1), 121-136.

Bugarim, M. C. C., Rodrigues, L. L., Pinho, J. C. C., \& Machado, D. Q. (2014b). Desempenho Dos Profissionais De Contabilidade No Exame De Suficiência Do CFC: Uma Análise De Conglomerados Regionais. Revista de Contabilidade e Organizações, 8(22), 60-71.

Camargo, R. V. W., Camargo, R. C. C. P., Andrade, D. F., \& Bornia, A. C. (2016). Desempenho dos alunos de ciências contábeis na prova ENADE/2012: Uma aplicação da Teoria da Resposta ao Item. Revista de Educação e Pesquisa em Contabilidade (REPEC), 10(3), 332-355.

Candiotto, L. B., \& Miguel, M. E. B. (2009, Outubro). O Curso De Ciências Contábeis na Educação Brasileira: Das aulas De Comércio Ao Curso Superior De Ciências Contábeis (1808-1951). Anais do Congresso Nacional de Educação-EDUCERE, Curitiba, 9. 
Constituição da República Federativa do Brasil de 1988. (1988). Recuperado de http://www. planalto.gov.br/ccivil_03/Constituicao/Constituicao.htm

Decreto 9.235, 2017. Recuperado de http://www.planalto.gov.br/ccivil_03/_Ato20152018/2017/Decreto/D9235.htm

Decreto-Lei 7.988, 1945. Recuperado de https://www2.camara.leg.br/legin/fed/declei/1940-1949/decreto-lei-7988-22-setembro-1945-417334-publicacaooriginal-1-pe.html

Decreto-Lei 9.295, 1946. Recuperado de http://www.planalto.gov.br/ccivil_03/decreto-lei/ Del9295.htm

Diehl, C. A., \& Souza, M. A. (2007). Formação, certificação e educação continuada: Um estudo exploratório do profissional contábil sob a óptica das empresas head hunters. BASE-Revista de Administração e Contabilidade da Unisinos, 4(7), 233-248.

Espejo, M. M. S. B., Ribeiro, F., Silva, P. Y. C., \& Oliveira, R. M. (2017). Conversação Necessária: Articulação Entre O Curso De Graduação Em Contabilidade E Os Programas De Pós-Graduação Stricto-Sensu Na Área. Contabilidade Vista \& Revista, 28(1), 1-24.

Fávero, L. P., Belfiore, P., Silva, F. L., \& Chan, B. L. (2009). Análise de dados: Modelagem multivariada para tomada de decisões. Rio de Janeiro: Campus: Elsevier.

Galvão, N. (2016). Percepção dos contadores sobre o exame de suficiência do CFC. Revista Catarinense da Ciência Contábil-CRCSC, 15(45), 49-62.

Gil, A. C. (2010). Como elaborar projetos de pesquisa. (5ª ed.). São Paulo: Atlas.

Gonzales, A., \& Ricardino, A. A., Filho. (2017). Transparência na divulgação de resultados do exame de suficiência do CFC. Revista Contabilidade \& Finanças, 28(1), 45-66.

Gujarati, D. N., \& Porter, D. C. (2011). Econometria básica. (5ª ed.). Porto Alegre: AMGH.

Instituto Nacional de Estudos e Pesquisas Educacionais Anísio Teixeira. (2002). Exame Nacional do Ensino Médio-Documento Básico. Brasília, DF: INEP.

Instituto Nacional de Estudos e Pesquisas Educacionais Anísio Teixeira. Sinopses Estatísticas da Educação Superior. (2018). Recuperado de http://portal.inep.gov.br/web/guest/ sinopses-estatisticas-da-educacao-superior 
Kounrouzan, M. C. (2011). A qualidade do ensino nos cursos de ciências contábeis e a formação do contador para atender o mercado de trabalho. Thêma et Scientia, 1(1), 17-26.

Lei 9.394, 1996. Recuperado de http://www.planalto.gov.br/Ccivil_03/leis/L9394.htm

Lei 12.249, 2010. Recuperado de http://www.planalto.gov.br/ccivil_03/_Ato2007-2010/2010/ Lei/L12249.htm\#art76

Lima, C. E. S., Silva, A. C. B., Campelo, K. S., \& Gonçalves, V. L. (2012). Exame de suficiência: Um estudo sobre a percepção de alunos concluintes de cursos de ciências contábeis do município de Caruaru-PE quanto a sua preparação face ao conhecimento adquirido na graduação. Anais do Congresso Brasileiro de Contabilidade, Belém, 19.

Lopes, A. C. T. (2009). Temas da Doutrina Científica da Contabilidade. São Paulo: Biblioteca24horas.

Madeira, G. J., Mendonça, K. F. C., \& Abreu, S. M. (2003). A disciplina teoria da contabilidade nos exames de suficiência e provão [Edição especial]. Contabilidade Vista \& Revista, 14(esp), 103-122.

Martins, C. M. F., Silva, C. B. A., Bernardo, D. C. R., \& Madeira, G. J. (2003). O desempenho do estado de Minas Gerais no sétimo exame de suficiência do CFC-março/2003. Contabilidade Vista \& Revista, 14, 81-102.

Martins, G. A., \& Theóphilo, C. R. (2009). Metodologia da Investigação Científica para Ciências Sociais Aplicadas. (2 ed.). São Paulo: Atlas.

Martins, O. S., Vasconcelos, A. F., \& Aguiar, P. (2009). IES Pública X IES Privada: Uma Investigação Sobre o Mito da Influência do Tipo de IES na Atuação Profissional do Contador. Revista Contabilidade Vista \& Revista, 20(2), 39-64.

Miranda, C. S., Araújo, A. M. P., \& Miranda, R. A. M. (2017). O exame de suficiência em contabilidade: Uma avaliação sob a perspectiva dos pesquisadores. Revista Ambiente Contábil, 9(16), 158-178.

Nascimento, C. D. L., \& Souza, M. A. (2005). Os indicadores sobre a qualidade dos cursos de Ciências Contábeis: Um estudo acerca dos resultados do ENC e do Exame de Suficiência. Anais do Congresso Internacional de Custos, Florianópolis, 9.

Nogueira, C. A. G., Nogueira, A. O., Almeida, S. F. D. C., Ribeiro, J. L., \& Chaves, V. T. L. (2013). Preparação para o exame de suficiência: Desafios para os docentes do curso de ciências contábeis. Anais do Encontro de Práticas Docentes, Fortaleza, 5. 
Peleias, I. R., Silva, G. P., Segreti, J. B., \& Chirotto, A. R. (2007). Evolução do ensino da contabilidade no Brasil: Uma análise histórica. Revista Contabilidade \& Finanças, 18(spe), 19-32.

Pinheiro, F. M. G., Dias, J. M., Filho, Lima, R. N., Filho, \& Lopes, L. M. S. (2013). O perfil do contador e os níveis de habilidades cognitivas nos exames Enade e suficiência do CFC: Uma análise sob a perspectiva da taxonomia de Bloom. Revista Contemporânea de Economia e Gestão, 11(1), 50-65.

Resolução CFC 853, 1999. Recuperado de http://wwwl.cfc.org.br/sisweb/SRE/docs/RES_853. pdf

Resolução CFC 1.486, 2015. Recuperado de http://wwwl.cfc.org.br/sisweb/SRE/docs/ Res_1486.pdf

Santos, C. A., Pinto, J. S., Gonçalves, M. L., \& Nunes, R. S. (2013). Exame de Suficiência: Percepção de docentes dos cursos de Ciências Contábeis das faculdades de Mato Grosso do Sul. Revista Brasileira de Contabilidade, 197, 64-77.

Santos, M. J. A., Pinheiro, L. B., Oliveira, J. W., Silva, S. G., Nogueira, M. S., Lima, A. V., ... Terra, B. (2014). Um estudo comparativo entre o exame de suficiência do conselho federal de contabilidade, o exame nacional de desempenho de estudantes e a pós-graduação stricto sensu dos cursos de ciências contábeis do Estado do Rio de Janeiro. Polêmica, 13(4), 1681-1698.

Silva, A. C. R., Gomes, S. M. S., Guimarães, I. P. (2008). Educação em Contabilidade: Alguns Aspectos Crítico-Sugestivos do Exame Nacional de Desempenho dos Estudantes Enade/2006. Anais do Congresso brasileiro de contabilidade, Gramado, 18.

Silva, R. M. P. (2008). Percepção de Formandos Em Ciências Contábeis Sobre Sua Preparação Para Ingresso no Mercado de Trabalho: Um estudo no âmbito dos cursos do Distrito Federal (Dissertação de mestrado). Universidade de Brasília/UFPB/UFPE/UFRN, Brasília, DF.

Stevenson, W. J. (1981). Estatística Aplicada à Administração. São Paulo: Harbra.

Viggiano, E., \& Mattos, C. (2013). O desempenho de estudantes no Enem 2010 em diferentes regiões brasileiras. Revista Brasileira de Estudos Pedagógicos, 94(237), 417-438. 


\section{Como citar este artigo:}

\section{ABNT}

MARÇAL, Ronan Reis et al. Avaliações de desempenho no ensino contábil brasileiro: uma análise comparativa entre IES diante do Exame de Suficiência do CFC. RACE, Revista de Administração, Contabilidade e Economia, Joaçaba: Editora Unoesc, v. 18, n. 2, p. COLO. CAR, maio/ago. 2019. Disponível em: http://editora.unoesc.edu.br/index.php/race. Acesso em: dia/mês/ano.

\section{APA}

Marçal, R. S., Matos, V. da S., Carvalho, T. F. M. de, \& Carvalho, M da S. (2019). Avaliações de desempenho no ensino contábil brasileiro: Uma análise comparativa entre IES diante do Exame de Suficiência do CFC. RACE, Revista de Administração, Contabilidade e Economia, 18(2), COLOCAR PÁGINA. Recuperado de http://editora.unoesc.edu.br/index. php/race 